\title{
PENGARUH MODEL PEMBELAJARAN COOPERATIVE SCRIPT BERBANTUAN MEDIA STRIP STORY TERHADAP KOMPETENSI PENGETAHUAN BAHASA INDONESIA
}

\author{
Luh Putu Agustina Wulandari ${ }^{1}$, I Nengah Suadnyana ${ }^{2}$, I Wayan Darsana ${ }^{3}$ \\ Jurusan Pendidikan Guru Sekolah Dasar, Universitas Pendidikan Ganesha, Singaraja, Indonesia \\ e-mail: wulandariagst44@gmail.com¹, inengah.suadnyana@undiksha.ac.id², \\ iwayan.darsana@undiksha.ac.id ${ }^{3}$
}

\begin{abstract}
Abstrak
Penelitian ini bertujuan untuk mengetahui pengaruh yang signifikan kompetensi pengetahuan Bahasa Indonesia antara kelompok siswa yang dibelajarkan melaluimodel pembelajaran cooperative script berbantuan media strip story dengan kelompok siswa yang tidak dibelajarkan melalui model pembelajaran cooperative script berbantuan media strip story pada siswa kelas IV SD Gugus IV Kuta Selatan tahun ajaran 2017/2018. Jenis penelitian ini merupakan eksperimen semu dengan desain penelitian nonequivalent control group design. Populasi penelitian ini adalah siswa kelas IV di SD Gugus IV Kuta Selatan tahun ajaran 2017/2018 yang berjumlah 416 orang. Sampel ditentukan dengan teknik random sampling. Sampel penelitian ini adalah siswa kelas IVA SD No. 10 Jimbaran sebagai kelompok eksperimen dan siswa kelas IVA SD No. 4 Jimbaran sebagai kelompok kontrol. Data penguasaan kompetensi pengetahuan Bahasa Indonesia dikumpulkan dengan instrumen berupa tes objektif pilihan ganda biasa berjumlah 23 butir soal yang divalidasi. Data penguasaan kompetensi pengetahuan Bahasa Indonesia dianalisis dengan t-test. Hasil analisis menunjukkan terdapat pengaruh yang signifikan penguasaan kompetensi pengetahuan Bahasa Indonesia antara kelompok siswa yang dibelajarkan melaluimodel pembelajaran cooperative script berbantuan media strip story dengan kelompok siswa yang tidak dibelajarkan melalui model pembelajaran cooperative script berbantuan media strip story pada siswa kelas IV SD Gugus IV Kuta Selatan tahun ajaran 2017/2018. Hal tersebut dibuktikan dengan hasil thitung $=6,842$ dan pada taraf signifikansi $5 \%(=0,05)$ dengan $\mathrm{dk}=(35+30)-2=63$ diperoleh ttabel $=2,000$. Berdasarkan kriteria pengujian thitung $=6,842>\operatorname{ttabel}(\alpha=0,05)=2,000$. Demikian pula nilai rerata penguasaan kompetensi pengetahuan Bahasa Indonesia siswa kelompok eksperimen $X_{1}=0,46>X_{2}=0,20$ rerata penguasaan kompetensi pengetahuan Bahasa Indonesia siswa kelompok kontrol. Dengan demikian dapat disimpulkan bahwa pembelajaran cooperative script berbantuan media strip story berpengaruh terhadap penguasaan kompetensi pengetahuan Bahasa Indonesia siswa kelas IV di SD Gugus IV Kuta Selatan tahun ajaran 2017/2018.
\end{abstract}

Kata kunci: Cooperative Script, strip story, kompetensi pengetahuan Bahasa Indonesia.

\section{Abstract}

This study aims to determine the significant effect of the knowledge competency of Bahasa Indonesia between the group of students who were studied through cooperative script learning model with strip story media with the group of students who were not studied through cooperative script learning model with strip story media on the fourth grade of students gugus IV Kuta Selatan academic year 2017/2018. This type of study is a quasi experiment with nonquivalent control group research design. The population of study is the fourth grade of students Gugus IV Kuta Selatan academic year $2017 / 2018$ in total 416 students. The sample is determined by random sampling technique. The sample of study is the students of class IVA SD No. 10 Jimbaran as experimental group and the students of class IVA SD No. 4 Jimbaran as control group. The mastery data of the knowledge competency of Bahasa Indonesia is collected by the instrument in form of 23 questions of multiplechoice objective test which is validated. The mastery data of the knowledge competency of Bahasa Indonesia is analyzed by $t$-test. The result of the analysis shows that there is a significant influence on the mastery of the knowledge competency of Bahasa Indonesia between the group of students who were studied through cooperative script learning model with strip story media with the group of students who were not studied through cooperative script learning model with strip story media on the fourth grade of students gugus IV Kuta Selatan academic year 2017/2018. It is proved by thitung = 6,842 and at the significant level $5 \%(=0,05)$ with $d k=(35+30)-2=63$ obtained ttabel $=2,000$. Based on test criteria thitung $=6,842>$ ttabel $(\alpha=0,05)=2,000$. As well as average score of the mastery of knowledge competency of Bahasa Indonesia of experimental students $X_{1}=0,46>X_{2}=0,20$ the average score of the mastery of knowledge competency of Bahasa Indonesia of control group 
students. Thus it can be concluded that cooperative script learning with story strip media influence on the mastery of the knowledge competency of Bahasa Indonesia on the fourth grade of students in SD Gugus IV Kuta Selatan academic year 2017/2018.

Keywords : Cooperative Script, strip story, the knowledge competency of Bahasa Indonesia.

\section{Pendahuluan}

Untuk menghadapi perkembangan IPTEK (Ilmu Pengetahuan dan Teknologi), dan tantangan masa depan pada era globalisasi ini, tentunya harus didasari dengan pembelajaran sebagai pondasi yang kokoh untuk menunjang keberhasilan dalam membangun pembelajaran dalam menciptakan sumber daya manusia (SDM) yang berkualitas. Pembelajaran yang berkualitas dipengaruhi oleh ketersediaan berbagai komponen pendukungnya. Salah satu komponen pendukung tersebut adalah kurikulum yang dikembangkan dan digunakan dalam proses pembelajaran. Pembelajaran merupakan proses interaksi peserta didik dengan pendidik dan sumber belajar pada suatu lingkungan belajar. Pembelajaran yang dimaksud berupa bantuan yang diberikan oleh pendidik yang tujuannya agar terjadi proses pemerolehan ilmu dan pengetahuan pada peserta didik.

Pembelajaran yang dilakukan tentunya berkaitan erat dengan komponen pendukung dalam pembelajaran itu sendiri, yaitu Kurikulum. Menurut Undang-undang Nomor 20 Tahun 2003 tentang Pendidikan Nasional, menyebutkan bahwa "Kurikulum adalah seperangkat rencana dan pengaturan mengenai tujuan, isi, dan bahan pelajaran serta cara yang digunakan sebagai pedoman penyelenggaraan kegiatan pembelajaran untuk mencapai tujuan pendidikan tertentu". Kurikulum 2013 sudah diterapkan di berbagai sekolah, terutama di Sekolah Dasar. Secara sederhana dapat diartikan bahwa kurikulum 2013 atau bisa juga disebut dengan kurikulum tematik merupakan kurikulum yang memuat konsep pembelajaran terpadu yang menggunakan tema untuk mengkaitkan beberapa mata pelajaran sehingga dapat memberikan pengalaman bermakna kepada para peserta didik. Kurikulum 2013 disebut juga kurikulum berbasis kompetensi dan karakter. Pembelajaran kurikulum 2013 adalah pembelajaran yang berpusat pada siswa, sehingga diperlukannya model pembelajaran untuk membantu meningkatkan pemahaman siswa terhadap materi pelajaran serta menarik minat belajar siswa agar siswa aktif, dan juga terciptanya suasana belajar aktif, efektif, efisien dan menyenangkan dalam proses pembelajaran di dalam kelas (Kemendikbud, 2013).

Berdasarkan hasil wawancara yang telah dilakukan di Sekolah Dasar, didapatkan permasalahan dalam pembelajaran Bahasa Indonesia. Bahasa Indonesia adalah salah satu materi pembelajaran yang diajarkan di Sekolah Dasar. Bahasa Indonesia di SD diarahkan untuk meningkatkan kemampuan siswa untuk berkomunikasi dalam Bahasa Indonesia dengan baik dan benar, baik secara lisan maupun tulisan. Observasi atau pengamatan ini dilakukan pada tanggal 6 Pebruari 2018, ditemukan suatu masalah yaitu masih kurangnya pemahaman siswa terhadap kompetensi pengetahuan Bahasa Indonesia karena kebanyakan siswa mengganggap bahwa pembelajaran Bahasa Indonesia sangat mudah untuk dikerjakan dalam proses pembelajarannya. Selain itu, proses pembelajarannya yang kurang menarik sehingga daya tarik peserta didik menurun dalam mengikuti pembelajaran di dalam kelas. Hal ini, tentunya akan mempengaruhi prestasi belajar dari siswa. Proses pembelajaran di dalam kelas kurang menarik, secara umum disebabkan karena pemilihan model pembelajaran kurang tepat yang akan menimbulkan kebosanan untuk siswa di dalam kelas, serta kurang adanya interaksi antara guru dengan siswa yang menyebabkan kompetensi pengetahuan siswa menjadi kurang optimal. Upaya yang dapat dilakukan untuk mengatasi permasalahan di atas adalah dengan menerapkan salah satu model pembelajaran yang sesuai dengan karakteristik peserta didik dan juga materi pelajaran yang akan diajarkan. Model pembelajaran yang dapat diterapkan adalah model pembelajaran kooperatif tipe Cooperative Script. Cooperative Script merupakan salah satu tipe pembelajaran kooperatif yang menempatkan peserta dalam kelompok-kelompok belajar 
secara berpasangan dan bergantian secara lisan dalam mengikhtisarkan bagian-bagian materi yang dipelajari. Agar model pembelajaran dapat berjalan dengan baik, tentu didukung oleh media sebagai sarana yang memadai dalam menunjang keberhasilan proses pembelajaran. Salah media yang digunakan adalah media pembelajaran strip story.

Dari uraian latar belakang yang telah dipaparkan, dapat diidentifikasi beberapa masalah, yaitu (a) penguasaan kompetensi pengetahuan Bahasa Indonesia siswa kelas IV di SD Gugus IV Kuta Selatan masih sangat rendah, (b) model pembelajaran yang digunakan dalam proses pembelajaaran Bahasa Indonesia tampak belum menggunakan model-model pembelajaran yang inovatif, (c) media pembelajaran seperti media strip story masih jarang digunakan dalam proses pembelajaran Bahasa Indonesia, dan (d) model pembelajaran Cooperative Script berbantuan media strip story belum pernah diterapkan di sekolah.

Berdasarkan pemaparan permasalah tersebut, maka dilakukan penelitian tentang "Pengaruh Model Pembelajaran Cooperative Script Berbantuan Media Strip Story Terhadap Kompetensi Pengetahuan Bahasa Indonesia Siswa Kelas IV SD Gugus IV Kuta Selatan Tahun Ajaran 2017/2018". Model pembelajaran cooperative script berbantuan media strip story adalah suatu model pembelajaran yang langkah-langkahnya sesuai dengan model cooperative script yang memfokuskan siswa untuk bekerja secara berpasangan dan bergantian secara lisan dalam mengikhtisarkan bagian-bagian materi yang dipelajari dan dibantu dengan media strip story dalam memberikan informasi yang akan disajikan. Cooperative Script juga memungkinkan siswa untuk menemukan ide-ide pokok dari gagasan besar yang disampaikan oleh guru. Dengan adanya model ini, diharapkan siswa bisa belajar menyimpulkan sendiri materi pelajaran yang telah ditentukan (Huda, 2013).

Menurut Krisno Budiyanto (2016: 36-37), menyatakan bahwa "Skrip kooperatif adalah model belajar dimana siswa diciptakan berpasangan dan secara lisan mengikhtisarkan bagian-bagian dari materi yang dipelajari". Berdasarkan beberapa pendapat yang dijelaskan, maka dapat disimpulkan bahwa model kooperatif pembelajaran tipe Cooperative Script adalah pembelajaran yang dilakukan secara berpasangan dan bergantian secara lisan dalam mengintisarikan bagian-bagian materi yang dipelajari. Di dalam proses belajar aktif, guru memiliki kewajiban untuk menyampaikan pengetahuan, pengalaman, dan pandangannya terhadap bahan yang mereka pelajari. Waktu untuk menyampaikan pesan dalam proses pembelajaran sangat terbatas, karena sebagian besar waktu belajar telah digunakan oleh para siswa untuk melakukan eksplorasi dan elaborasi. Oleh sebab itu, para guru diharapkan mampu menyajikan bahan-bahan yang akan disampaikan secara efisien, dalam waktu yang singkat tetapi banyak informasi yang dapat disajikan, agar pembelajaran yang dilaksanakan menjadi lebih efektif dalam menyampaikan bahan dan informasi pengetahuan, serta memiliki daya tarik bagi para siswa untuk memperhatikannya. Dengan demikian, media adalah bagian yang tidak terpisahkan dari proses belajar mengajar demi terciptanya tujuan pendidikan. Adapun media yang digunakan untuk mendukung model pembelajaran ini adalah media strip story. Strip story merupakan media visualitas yang memerlukan pengelihatan siswa untuk menangkap setiap pembelajaran, visualisasi pesan, informasi atau konsep yang akan disampaikan kepada siswa dapat dikembangkan dalam berbagai bentuk, seperti foto, gambar atau ilustrasi, sketsa atau gambar garis, grafik, bagan, chart, dan gabungan dari dua bentuk atau lebih. Strip story merupakan potongan-potongan kertas yang sering digunakan dalam pengajaran bahasa. Selain murah dan amat mudah untuk dibuat, teknik strip story sederhana dan tidak memerlukan keterampilan khusus untuk menggunakannya (Azhar Arsyad, 2016).

\section{Metode}

Penelitian ini dilaksanakan di kelas IV SD Gugus IV Kuta Selatan. Penelitian ini merupakan penelitian kuantitatif dengan jenis penelitian, yaitu eksperimen semu (quasi eksperiment). Desain yang digunakan yaitu "Nonequivalentt Control Group Design". Dalam desain ini terdapat dua kelompok, yaitu kelompok eksperimen dan kelompok kontrol. Desain penelitian dapat dilihat pada gambar di bawah ini. 


\begin{tabular}{|cccc|}
\hline $\mathrm{O}_{1}$ & $\mathrm{X}$ & $\mathrm{O}_{2}$ & (eksperimen) \\
$\mathrm{O}_{3}$ & & $\mathrm{O}_{4}$ & (kontrol) \\
& & & \\
\hline
\end{tabular}

Gambar 1.Rancangan penelitian nonequivalent control group design

\author{
Keterangan : \\ O1 = Pre-test pada kelompok eksperimen. \\ $\mathrm{O} 2$ = Post-test pada kelompok \\ eksperimen. \\ O3 = Pre-test pada kelompok kontrol. \\ O4 = Post-test pada kelompok kontrol. \\ $\mathrm{X}=$ Perlakuan dengan model \\ Cooperative Script berbantuan \\ media strip story pada kelas eksperimen.
}

Dalam penelitian ini untuk menentukan subjek penelitian langkah awal dalam penelitian ini adalah menentukan populasi yang akan diteliti. Menurut Sugiyono (2017: 80) menyatakan bahwa populasi adalah wilayah generalisasi yang terdiri atas obyek/subyek yang mempunyai kualitas dan karakteristik tertentu yang ditetapkan oleh peneliti untuk di pelajari dan kemudian ditarik kesimpulannya.

"Keseluruhan dari objek, orang, peristiwa, atau sejenisnya yang menjadi perhatian dan kajian dalam penelitian" (Setyosari, 2015: 221). Jadi, populasi adalah sekumpulan objek atau subjek pada suatu tempat yang memiliki karakteristik tertentu dan ditetapkan oleh peneliti untuk dipelajari dan ditarik kesimpulannya. Populasi dalam penelitian ini adalah siswa kelas IV SD Gugus IV Kuta Selatan Tahun Ajaran 2017/2018, yang terdiri dari 416 orang siswa,

Selanjutnya adalah menentukan sampel. "Sampel adalah bagian dari jumlah dan karakteristik yang dimiliki oleh populasi tersebut" (Sugiyono, 2017: 81). Sedangkan Setyosari (2015: 221) menyebutkan bahwa sampel adalah sekelompok objek, orang, peristiwa, dan sebagainya yang merupakan representasi dari keseluruhan. Jadi, dapat disimpulkan bahwa pengertian dari sampel adalah sebagian dari jumlah populasi yang dapat mewakili karakteristik yang dimiliki oleh populasi tersebut.

Dalam penelitian ini yang dipilih adalah dua kelas, yaitu satu kelas yang dijadikan sebagai kelas eksperimen dan satu kelas dijadikan sebagai kelas kontrol. Pengambilan sampel dalam penelitian ini menggunakan teknik sampling acak (random sampling). Pengambilan sampel dengan teknik random sampling pada penelitian ini dilakukan dengan cara undian. Setelah terpilihnya kelas eskperimen dan kelas control, selanjutnya kelas-kelas tersebut akan diberikan pretest. Nilai atau skor dari hasil pretest dianalisis menggunakan uji t. Sebelum uji kesetaraan menggunakan uji t, maka data hasil pretest diuji prasyarat yaitu uji normalitas dan homogenitas. Jika data pretest yang diperoleh sudah memenuhi prasyarat uji normalitas dan homogenitas maka dianalisis menggunakan uji t. Kesetaraan sampel diuji dengan rumus uji-t dengan polled varian

Dengan kriteria pengujian, pada taraf signifikansi $5 \%$ dengan $\mathrm{dk}=\mathrm{n} 1+\mathrm{n} 2-2$. jika harga t_hitung< t_tabel, maka Ho diterima dan Ha ditolak, dan jika harga t_hitung $>\mathrm{t}$ tabel maka Ho ditolak dan Ha diterima. Sebelum dilakukan uji kesetaraan, terlebih dahulu dilakukan uji prasyarat analisis yang meliputi uji normalitas sebaran data dan uji homogenitas varians. Uji normalitas kedua sampel dilakukan menggunakan analisis 
Kolmogorov-Smirnov. Adapun rekapitulasi hasil uji normalitas sebaran data pretest kompetensi pengetahuan Bahasa Indonesia pada siswa kelas IV SD Gugus IV Kuta Selatan pada tabel sebagai berikut.

Tabel 1 : Rekapitulasi Hasil Uji Normalitas Sebaran Data Pretest Kompetensi Pengetahuan Bahasa Indonesia

\begin{tabular}{ccccc}
\hline No & Sampel & Nilai Maksimum & $\begin{array}{c}\text { Nilai tabel } \\
\text { Kolmogorov-Smirnov }\end{array}$ & Keterangan \\
\hline 1 & SD No. 10 Jimbaran & 0,140 & 0,224 & Normal \\
2 & SD No. 4 Jimbaran & 0,221 & 0,242 & Normal \\
\hline
\end{tabular}

Berdasarkan perhitungan hasil uji normalitas sebaran data pretest SD No. 10 Jimbaran, diperoleh nilai maksimum $=0,140$ dan nilai tabel Kolmogorov-Smirnov $(\alpha=0,05)=$ 0,224 , karena nilai maksimum $=0,140<$ nilai tabel Kolmogorov-Smirnov $(\alpha=0,05)=0,224$ maka data berdistribusi normal. Berdasarkan perhitungan hasil uji normalitas sebaran data pretest SD No. 4 Jimbaran nilai maksimum $=0,221$ dan nilai tabel Kolmogorov-Smirnov $(\alpha=0,05)=0,242$, karena nilai maksimum $=0,221<$ nilai tabel Kolmogorov-Smirnov $(\alpha=0,05)$ $=0,242$ maka data berdistribusi normal.

Setelah uji normalitas sebaran data dilakukan, selanjutnya dilakukan uji homogenitas varians data pretest kompetensi pengetahuan Bahasa Indonesia. Adapun rekapitulasi hasil uji homogenitas varians dengan menggunakan uji $F$ sebagai berikut.

Tabel 2 : Rekapitulasi Hasil Uji Homogenitas Varians Data Pretest Kompetensi Pengetahuan Bahasa Indonesia.

\begin{tabular}{ccccccc}
\hline Sampel & $S_{1}^{2}$ & $S_{2}^{2}$ & Dk & $F_{\text {hitung }}$ & $F_{\text {tabel }}$ & Keterangan \\
\hline Uji Homogenitas & 137,43 & 137,52 & 29,34 & 1,00 & 1,80 & Homogen \\
\hline
\end{tabular}

Berdasarkan uji homogenitas, Fhitung $=1,00$ dan Ftabel $(\alpha=0,05)=1,80$, karena Fhitung $=1,00<$ Ftabel $(\alpha=0,05)=1,80$ maka data homogen. Karena data pretest kedua kelompok sampel berdistribusi normal dan homogen dilanjutkan dengan melakukan uji kesetaraan dengan uji-t. Adapun hasil analisis uji kesetaran pretest kompetensi pengetahuan Bahasa Indonesia sebagai berikut.

Tabel 3 : Hasil Analisis Kesetaraan Sampel Pretest

\begin{tabular}{llllllcccc}
\hline No & \multicolumn{2}{c}{ Sampel } & & $\mathrm{N}$ & $\mathrm{Dk}$ & $\mathrm{X}$ & $\mathrm{S}^{2}$ & $\mathrm{t}_{\text {hitung }}$ & $\mathrm{t}_{\text {tabel }}$ \\
\hline 1 & $\begin{array}{l}\text { Kelas IV } \\
\text { Jimbaran }\end{array}$ & No. & 10 & 35 & & 63,97 & 137,43 & & \\
2 & $\begin{array}{l}\text { Kelas IV SD } \\
\text { Jimbaran }\end{array}$ & No. 4 & 30 & 63 & 62,46 & 137,52 & 0,576 & 2.000 \\
\hline
\end{tabular}

Berdasarkan hasil analisis, diperoleh thitung $=0,576$ dan ttabel pada taraf signifikansi $5 \%$ dengan derajat kebebasan $\mathrm{dk}=(\mathrm{n} 1+\mathrm{n} 2-2)=2,000$. Sehingga thitung $=0,576<$ ttabel $(\alpha=0,05)=2,000$. Berdasarkan uji-t kesetaraan yang telah dilakukan diperoleh bahwa kedua kelas tersebut setara. Pengundian tahap kedua untuk menentukan kelompok eksperimen dan kelompok kontrol. Kelas yang muncul pertama saat diundi dijadikan sebagai kelompok eksperimen, sedangkan kelas yang muncul kedua dijadikan sebagai kelompok kontrol. Berdasarkan hasil undian, diperoleh kelas IV SD No. 10 Jimbaran berjumlah 35 siswa yang muncul pertama dijadikan sebagai kelompok eksperimen dan kelas IV SD No. 4 Jimbaran berjumlah 30 siswa yang muncul kedua dijadikan sebagai kelompok kontrol.

Dalam menganalisis data digunakan metode analisis statistik deskriptif dan statistik inferensial. Pada statistik deskriptif, data yang akan dianalisis adalah data post test 
kompetensi pengetahuan Bahasa Indonesia siswa pada kelompok eksperimen dan siswa pada kelompok kontrol. Sedangkan, pada statistik inferensial data yang dianalisis adalah gain skor dari hasil pre test dan post test. "Statistik deskriptif adalah suatu cara pengolahan data yang dilakukan dengan jalan menerapkan rumus- rumus statistik deskriptif untuk menggambarkan suatu objek/variabel tertentu, sehingga diperoleh kesimpulan umum" (Agung, 2014:110). Selanjutnya, Statistik inferensial, sering dengan rumus polled varians. Rumus uji-t dengan rumus polled varians digunakan bila jumlah anggota sampel sama $n_{1}=$ $\mathrm{n}_{2}$ atau $\mathrm{n}_{1} \neq \mathrm{n}_{2}$ dan varians homogen. disebut statistik induktif atau statistik probabilitas, adalah tenik statistik yang digunakan untuk menganalisis data sampel dan hasilnya diberlakukan untuk populasi (Sugiyono, 2017: 148). Setelah statistic deskriptif dan iferensial dilakukan, $\mathrm{H}_{0}$ : Tidak terdapat perbedaan yang signifikan kompetensi pengetahuan Bahasa Indonesia antara kelompok siswa yang dibelajarkan dengan menggunakan model pembelajaran Cooperative Script berbantuan media strip story dengan kelompok siswa yang tidak dibelajarkan dengan menggunakan model pembelajaran Cooperative Script berbantuan media strip story pada kelas IV SD Gugus IV Kuta Selatan Tahun Ajaran 2017/2018.

$$
\begin{aligned}
& \text { Ho }: \boldsymbol{\mu 1}=\boldsymbol{\mu} \mathbf{2} \text { (Tidak Beda) } \\
& \text { Ha }: \boldsymbol{\mu 1} \neq \boldsymbol{\mu} \mathbf{2} \text { (Berbeda) } \\
& \text { (Sugiyono, 2017:163) }
\end{aligned}
$$

\section{Keterangan :}

$\mu 1=$ rata-rata kompetensi pengetahuan Bahasa Indonesia kelompok siswa yang dibelajarkan dengan model pembelajaran Cooperative Script berbantuan media strip story

$\mu 2$ = rata-rata kompetensi pengetahuan Bahasa Indonesia kelompok siswa yang tidak dibelajarkan dengan model pembelajaran Cooperative Script berbantuan media strip story.

Jika data yang diperoleh sudah memenuhi prasyarat uji normalitas dan uji homogenitas maka analisis yang digunakan adalah statistik parametrik. Analisis

\section{Hasil dan Pembahasan}

Uji homogenitas varian dilakukan berdasarkan data kompetensi pengetahuan Bahasa Indonesia yang menggunakan data gain skor kelompok yang dibelajarkan melalui model pembelajaran Cooperative Script berbantuan media strip story dan kelompok yang tidak dibelajarkan melalui model pembelajaran Cooperative Script berbantuan media strip story. Jumlah masing-masing kelompok analisis adalah 35 untuk kelompok eksperimen dan 30 untuk kelompok kontrol. Untuk menentukan homogenitas variansnya menggunakan uji F. Kriteria pengujian, jika haga Fhitung < Ftabel maka sampel homogen. Sebaliknya jika harga Ftabel > Ftabel maka sampel tidak homogen. Pengujian dilakukan pada taraf signifikansi 5\% dengan derajat kebebasan untuk pembilang n1-1 dan derajat kebebasan untuk penyebut n21. Pengujian homogenitas varian dapat dijabarkan sebagai berikut

Tabel 4 : Hasil Uji Homogenitas Varian Data Gain Skor Kompetensi Pengetahuan Bahasa Indonesia

\begin{tabular}{lcccc}
\hline \multicolumn{1}{c}{ Sampel } & Varian & $\mathrm{F}_{\text {hitung }}$ & $\mathrm{F}_{\text {tabel }}$ & Keterangan \\
\hline Kelompok eksperimen & 0,032 & 1,14 & 1,83 & Homogen \\
Kelompok Kontrol & 0,028 & & & \\
\hline
\end{tabular}

Dari hasil perhitungan, diperoleh Fhitung $=1,14$ sedangkan Ftabel pada taraf signifikansi $5 \%$ dengan $\mathrm{dk}(34,29)$ adalah 1,83. Ini berarti Fhitung $=1,14<$ Ftabel $(\alpha=0,05)$ $=1,83$ maka data homogen. 
Hipotesis penelitian yang diuji adalah Ho, yaitu tidak terdapat pengaruh yang signifikan kompetensi pengetahuan Bahasa Indonesia antara kelompok siswa yang dibelajarkan melalui model pembelajaran Cooperative Script berbantuan media strip story dengan kelompok siswa yang tidak dibelajarkan melalui model pembelajaran Cooperative Script berbantuan media strip story pada siswa kelas IV SD Gugus IV Kuta Selatan tahun ajaran 2017/2018. Berdasarkan hasil uji normalitas sebaran data dan uji homogenitas varians diperoleh data kedua kelompok berdistribusi normal dan varians kedua kelompok homogen, maka uji statistik yang digunakan dalam penelitian ini adalah uji-t dengan rumus polled varians. Dengan kriteria pengujian adalah Ho ditolak jika thitung > ttabel. Ttabel dihitung dengan $\mathrm{dk}=\mathrm{n} 1+\mathrm{n} 2-2, \mathrm{dk}=35+30-2=63$ pada taraf signifikansi $5 \%$..Berdasarkan rata-rata gain skor kelompok eksperimen yaitu 0,46 dengan varian yaitu 0,032 sedangkan kelompok kontrol diperoleh rata-rata yaitu 0,20 dengan varian yaitu 0,028 . Pada penelitian ini masing-masing siswa pada kelompok ekperimen berjumlah 35 orang dan kelompok kontrol berjumlah 30 orang. Dari hasil uji prasyarat yaitu uji normalitas sebaran data dan homogenitas diperoleh bahwa data dari kelompok eksperimen dan kelompok kontrol berdistribusi normal dan homogen. Berdasarkan hal tersebut, uji hipotesis menggunakan rumus polled varians. Pengujian hipotesis dijabarkan sebagai berikut

Tabel 5 : Hasil Uji Hipotesis

\begin{tabular}{lcccccc}
\hline \multicolumn{1}{c}{ Sampel } & Rata-rata & Varians & $\mathrm{N}$ & $\mathrm{t}_{\text {hitung }}$ & $\mathrm{t}_{\text {tabel }}$ & Kesimpulan \\
\hline $\begin{array}{l}\text { Kelompok } \\
\begin{array}{l}\text { Eksperimen } \\
\text { Kelompok }\end{array}\end{array}$ & 0,46 & 0,032 & 35 & & & \\
\begin{tabular}{l} 
Kontrol \\
\hline
\end{tabular} & 0,20 & 0,028 & 30 & 6,842 & 2,000 & $\mathrm{H}_{0}$ ditolak \\
\hline
\end{tabular}

Hasil analisis uji-t diperoleh thitung $=6,842$. Harga tersebut kemudian dibandingkan dengan harga ttabel dengan $\mathrm{dk}=35+30-2=63$ dan taraf signifikansi $5 \%$ sehingga diperoleh ttabel $=2,000$ karena thitung $=6,842>$ ttabel $=2,000$ maka $\mathrm{H}_{0}$ ditolak. Hal ini berarti terdapat pengaruh yang signifikan kompetensi pengetahuan Bahasa Indonesia antara kelompok siswa yang dibelajarkan melalui model pembelajaran Cooperative Script berbantuan media strip story dengan kelompok siswa yang tidak dibelajarkan melalui model pembelajaran Cooperative Script berbantuan media strip story pada siswa kelas IV SD Gugus IV Kuta Selatan tahun ajaran 2017/2018. Rata-rata gain skor kompetensi pengetahuan Bahasa Indonesia siswa kelompok eksperimen $\mathrm{Me}=0,46>\mathrm{Me}=0,20$ ratarata kompetensi pengetahuan Bahasa Indonesia kelompok kontrol, sehingga dapat disimpulkan bahwa model model pembelajaran Cooperative Script berbantuan media strip story berpengaruh terhadap kompetensi pengetahuan Bahasa Indonesia pada siswa kelas IV SD Gugus IV Kuta Selatan tahun ajaran 2016/2017.

Berdasarkan hasil analisis menggunakan uji-t diperoleh thitung = 6,842 . Kemudian dibandingkan dengan ttabel dengan $\mathrm{dk}=63$ pada taraf signifikansi $5 \%$ diperoleh ttabel $=2,000$. Karena thitung $=6,842>$ ttabel $(\alpha=0,05)=2,000$, maka dapat disimpulkan bahwa hipotesis yang menyatakan terdapat pengaruh yang signifikan kompetensi pengetahuan Bahasa Indonesia antara kelompok siswa yang dibelajarkan melalui model pembelajaran Cooperative Script berbantuan media strip story dengan kelompok siswa yang tidak dibelajarkan melalui model pembelajaran Cooperative Script berbantuan media strip story pada siswa kelas IV SD Gugus IV Kuta Selatan tahun ajaran 2017/2018 diterima. Rata-rata gain skor kompetensi pengetahuan Bahasa Indonesia kelompok yang dibelajarkan melalui model pembelajaran Cooperative Script berbantuan media strip story yaitu 0,46. Dari rata-rata tersebut, kemudian dikategorikan pada pada Penilaian Acuan Norma (PAN) skala lima. Rata-rata gain skor kelompok eksperimen dapat dikategorikan cukup baik. Rata-rata gain skor kompetensi pengetahuan Bahasa Indonesia kelompok siswa yang tidak dibelajarkan melalui model pembelajaran Cooperative Script berbantuan media strip story yaitu 0,20. Dari rata-rata tersebut, kemudian diketegorikan 
pada pada Penilaian Acuan Norma (PAN) skala lima. Rata-rata kelompok kontrol dapat dikategorikan cukup. Berdasarkan pengkategorian pada PAN skala lima kelompok eksperimen dan kelompok kontrol dikategorikan cukup. Namun dilihat dari rata-rata gain skor yang diperoleh bahwa kelompok eksperimen memiliki rata-rata lebih tinggi dibandingkan dari rata-rata kelompok kontrol. Hal ini berarti kelompok yang dibelajarkan melalui model pembelajaran Cooperative Script berbantuan media strip story berpengaruh terhadap kompetensi pengetahuan Bahasa Indonesia pada siswa kelas IV SD Gugus IV Kuta Selatan tahun ajaran 2017/2018.

Dengan demikian, model pembelajaran Cooperative Script berbantuan media strip story dapat direkomendasikan dalam membelajarkan siswa khususnya pada kegiatan pembelajaran untuk mengukur kompetensi pengetahuan Bahasa Indonesia pada siswa kelas IV. Kegiatan pembelajaran menggunakan model pembelajaran Cooperative Script berbantuan media strip story yang dilaksanakan di kelas eksperimen menunjukkan bahwa siswa dapat memperdalam pemahamannya mengenai materi pembelajaran, melatih tanggung jawab siswa dalam mengerjakan tugas yang diberikan, siswa merasa senang, dapat mengembangkan rasa ingin tahu, meningkatkan rasa percaya diri, dan mengembangkan rasa saling memiliki kerjasama antar siswa. Kegiatan pembelajaran menggunakan model pembelajaran Cooperative Script berbantuan media strip story memberikan hasil belajar dalam kompetensi pengetahuan yang lebih tinggi pada siswa karena model pembelajaran Cooperative Script berbantuan media strip story memiliki kelebihan dalam kegiatan pembelajaran, sehingga kegiatan pembelajaran lebih inovatif dan variatif.

\section{Simpulan dan Saran}

Penguasaan kompetensi pengetahuan Bahasa Indonesia kelompok yang dibelajarkan melalui model pembelajaran Cooperative Script bentauan media strip story pada siswa kelas IV SD Gugus IV Kuta Selatan tahun ajaran 2017/2018 diperoleh rata-rata gain skor yaitu 0,46, maka rata-rata kelompok eksperimen dapat dikategorikan cukup. Kompetensi pengetahuan Bahasa Indonesia kelompok yang tidak dibelajarkan melalui model pembelajaran Cooperative Script bentauan media strip story pada siswa kelas IV SD Gugus IV Kuta Selatan tahun ajaran 2017/2018 diperoleh rata-rata gain skor yaitu 0,20, maka ratarata kelompok kontrol dapat dikategorikan cukup.

Berdasarkan hasil analisis menggunakan uji $t$ diperoleh hasil analisis uji-t diperoleh thitung $=6,842$. Harga tersebut kemudian dibandingkan dengan harga ttabel dengan $\mathrm{dk}=$ $35+30-2=63$ dan taraf signifikansi $5 \%$ sehingga diperoleh ttabel $=2,000$ karena thitung $=$ $6,842>$ ttabel $=2,000$ maka $\mathrm{H}_{0}$ ditolak. Terdapat perbedaan yang signifikan penguasaan kompetensi pengetahuan Bahasa Indonesia antara kelompok siswa yang dibelajarkan melalui model pembelajaran Cooperative Script bentauan media strip story dengan kelompok siswa yang tidak dibelajarkan melalui model pembelajaran Cooperative Script bentauan media strip story. Dengan pemaparan tersebut, rata-rata penguasaan kompetensi Bahasa Indonesia pada kelompok eksperimen 0,46 lebih besar dibandingkan rata-rata penguasaan kompetensi Bahasa Indonesia pada kelompok kontrol 0,20. Sehingga dapat disimpulkan bahwa terdapat pengaruh model pembelajaran Cooperatif Script berbantuan media strip story terhadap kompetensi pengetahuan Bahasa Indonesia siswa kelas IV SD Gugus IV Kuta Selatan tahun ajaran 2017/2018.

Adapun saran yang dapat disampaikan setelah dilaksanakan dan diperoleh hasil dari penelitian yaitu sebagai berikut. 1) Siswa, disarankan kepada siswa agar memanfaatkan kesempatan yang difasilitasi guru dengan berpartisipasi aktif dalam kegiatan pembelajaran menggunakan model pembelajaran Cooperative Script berbantuan media strip story sehingga dapat membangun pengetahuan sendiri, 2) Guru, disarankan kepada guru agar lebih kreatif untuk memberikan fasilitas berupa sumber belajar dan kesempatan yang lebih besar bagi siswa pada pembelajaran dengan menggunakan model pembelajaran Cooperative Script berbantuan media strip story sehingga tercipta pembelajaran bermakna bagi siswa, 3) Sekolah, disarankan kepada kepala sekolah agar dapat menggunakan hasil 
penelitian ini sebagai pendukung sumber belajar guru dalam meningkatkan kualitas pembelajaran dengan menciptakan pembelajaran yang menggembirakan di sekolah sehingga sekolah mampu menghasilkan siswa yang memiliki output berkualitas dan 4) Peneliti Lain, disarankan kepada peneliti agar hasil penelitian ini digunakan sebagai referensi untuk melaksanakan penelitian selanjutnya atau menemukan inovasi kegiatan pembelajaran lainnya yang bermakna bagi siswa

\section{Daftar Pustaka}

Arikunto, Suharsimi. 2015. Dasar-dasar Evaluasi Pendidikan. Jakarta: Bumi Aksara.

Arsyad, Azhar. 2017. Media Pembelajaran.Jakarta: Rajawali Pers.

Asriyani, Sri. (2017). "Pengaruh Model Pembelajaran Cooperative Script Berbantuan Cerita Rakyat Terhadap Literasi Siswa Kelas III SD Gugus Kecamatan Klungkung Kabupaten Klungkung Tahun Pelajaran 2016/2017".Pacasarjana Universitas Pendidikan Ganesha, Volume 5, Nomor 2 (diakses tanggal 9 Januari 2018).

Budiyanto, Krisno.2016. Sintaks 45 Model Pembelajaran dalam Sudent Centered Learning (SCL). Malang:Universitas Muhammadiyah.

Dantes, Nyoman. 2012. Metode Penelitian. Yogyakarta: C. V. Andi Offset.

Setyosari, Punaji. 2015. Metode PenelitianPendidikan dan Pengembangan.Jakarta: PT. Kharisma Putra Utama

Sugiyono. 2017. Metode Penelitian.Bandung: Alfabeta.

Susanto, Ahmad. 2013. Teori Belajar dan Pembelajaran di Sekolah Dasar. Jakarta: Kharisma Putra Utama.

Tarigan, Henry Guntur. 2015. Membaca Sebagai Suatu Keterampilan Berbahasa. Bandung: Angkasa.

Taufina, 2016. Mozaik Penilaian Pembelajaran Dan Apresiasi Sastra Indonesia di Sekolah Dasar. Bandung: Angkasa. 